\title{
Estudio de la transversalidad de los contenidos en Educación Física a través de los currículos competenciales Study of the transversality of the contents in Physical Education through the competency-based curricula
}

\author{
Josep Solà Santesmases \\ Universidad Ramon Llull (España)
}

\begin{abstract}
Resumen. El artículo tiene por objetivo analizar la evolución de los currículos competenciales a través del estudio de la transversal idad de los conocimientos mediante el análisis documental de las principales regulaciones jurídicas educativas. El análisis de contenido permitirá un enfoque transversal sincrónico para comparar las leyes y RD estatales con los decretos y normativas autonómicas catalanas, y un enfoque longitudinal diacrónico para comparar la evolución de los currículos competenciales desde su aparición en la LO E hastasu consolidación en la LO M CE. Dicho análisis de contenido se fundamentará en las regulaciones paralaEducación Secundaria O bligatoria(ESO ) através de lamateriaespecíficaEducación Física, contrastando las ejemplificaciones prácticas con la materia troncal de matemáticas. Las conclusiones determinan el florecimiento de las competencias en los currículos y el asentamiento de la transversalidad como intervención necesaria para su logro. De una transver sal idad centrada en los contenidos disciplinares como metodología competencial (conexiones con las otras materias) se evoluciona a la transversal idad basada en las competencias y en la transferibilidad de los conocimientos a contextos reales (tratamiento gl obalizado de los contenidos).
\end{abstract}

Palabras clave. Currículum, competencias, transversalidad, conexiones con otras materias, globalidad de contenidos, educación física, educación secundaria obligatoria.

\begin{abstract}
The article aims to analyse the evolution of competency-based curricula through the study of the transversality of knowledge of the main educational legal regulations. The content analysis will allow a synchronous transversal approach to compare the state laws with the decrees of the autonomous administration, and adiachronic longitudinal approach to compare the evolution of the competences curricula from its appearance in the LOE to its consolidation in the LOMCE. Physical Education, a specific subject, will support the exemplification, contrasting it with the core mathematics subject. The conclusions determine the flourishing of competencies in the curricula and the establishment of transversal ity as a methodological aspect necessary for its achievement. From atransversality focused on disciplinary contents asa competency methodology (connections with other subjects) it evolvesto transversal ity based on competences and on the transferability of knowledge to real contexts (globalized treatment of content).
\end{abstract}

Key words: Currículum, competencies, transversality, connections with other subjects, gl obal content, physical education, compulsory secondary education.

Competencias y transversalidad en los currículos contemporáneos

La irrupción de las competencias en el sistema educativo español al inicio del siglo XXI determinó la ordenación de los primeros currículos competenciales a través de la Ley O rgánica de Educación 2/ 2006 (LO E) y la vigente Ley de M ejora de la Calidad Educativa 8/ 2013 (LOMCE). Las competencias, claramente establecidas como elementos curriculares en ambas leyes, Ilevaban implícitamente asociado el concepto de transversalidad o integración de conocimientos. Las ordenaciones derivadas de ambas leyes configuraron el sistema educativo

Fecha recepción: 02-07-20. Fecha de aceptación: 23-11-20

Camila Bonjour

bonjourca12@gmail.com español basado en competencias. El primer currículo competencial de la Educación Secundaria O bligatoria (ESO) fue desarrollado por el Real Decreto 1631/ 2006: «Las competencias básicas, que se incorporan por primera vez a las enseñanzas mínimas, permiten identificar aquellos aprendizajes que se consideran imprescindibles desde un planteamiento integrador y orientado a la aplicación de los saberes adquiridos» (p.4).

La aparición de las competencias no se limitó a la educación básica, denominación LOE a los diez años de educación obligatoria y gratuita compuesta por la Educación Primaria (6-12 años) y la Educación Secundaria O bligatoria (12-16 años). En los ciclos formativos se redactaron competencias profesionales de cada ámbito y se concretaron curricularmente las unidades de competencia (art. 39 LOE). En la U niversidad, la exigencia del Espacio Europeo de Educación Superior (2015) tam- 
bién enfatizó que los nuevos currículos de G rado fueran redactados competencialmente (RD 1393/ 2007 de O rdenación de las Enseñanzas U niversitarias).

Considerando la Ley O rgánica General del Sistema Educativo 1/ 1990 (LO GSE) como lareformaquetransformó profundamente la estructura del sistema educa tivo, en sus documentos no se hall laba referencia al guna ni a las competencias ni a la transversalidad. La LOGSE estableció las actuales etapas educativas y enfatizó la adecuada valoración de la educación especial, la sensibilidad por la educación de adultos o la compensación de desigualdades(Bunes, Calzón, Elexpuru, Fañanas, M uñozRepiso yValle, 1993). Sin embargo, a pesar de la innovación ideológicade dichaley, el actual concepto decompetencia era inexistente.

Un sencillo análisis cuantitativo revela que en la LO GSE la palabra «competencia/ s» aparece tan sólo en 13 ocasiones, y nunca con el significado actual vinculado al modelo curricular. En los noventa, el significado de competencia era el del «ámbito legal de atribuciones que corresponde a una entidad pública 0 a una autoridad jurídica 0 administrativa» (Real Academia Espa ñola [RAE], 2018), focalizándolo especialmente en las comunidades autónomas paragestionar la educación. Sin embargo, la LO E (2006) presenta la pal abra competencia, en singular, en 21 ocasiones, incrementándose hasta 82 ocasiones el vocablo en plural. Por lo tanto, la pala bra «competencia/ s» aparece en 103 ocasiones. Un incréble aumento porcentual del $700 \%$ en 16 años. Semejante evolución conceptual se mantieneen laLO M CE (2013), que presenta la misma palabra «competencial s» en 80 referencias textuales. En general, tanto la LOE como la LOMCE mantienen el término "competencia» en singular para expresar el mismo significado de la LOGSE, pero ambas leyes tienden a utilizar el término «competencias» en plural en su segunda acepción: «Pericia, aptitud o idoneidad para hacer algo o intervenir en un asunto determinado» (RAE, 2019), significa do más próximo a la definición del actual currículo competencial.

La primera aparición del concepto competencia en la legislación educativa española fue discreta, en el preámbulo de la LOE (2006): «Especial interés reviste la inclusión de las competencias básicas entre los componentes del currículo, por cuanto debe permitir ca racterizar de manera precisa la formación que deben recibir los estudiantes» (p. 10). El análisis del concepto coincidió con múltiples publicaciones en la literatura educativa con el fin de perfilar su significado y acotar susámbitosdeactuación (LeBoterf, 2000; Lévy-Leboyer,
2003; Riera, 2005; Perrenoud, 2007). N ormativamente, la definición original de competencias se redactó como «capacidades para aplicar de forma integrada los contenidos propios de cada enseñanza y etapa educativa, con el fin de lograr la realización adecuada de actividades y la resolución eficaz de problemas complejos» (art. 6 $L O E)$ y se mantuvo prácticamente idéntica en su formulación actual (art. 6 LOMCE). Además, se insistía que en la ESO debía prestarse «una atención especial a la adquisición y el desarrollo de las competencias básicas» como primer principio pedagógico (art. 26 LOE). Como aspectos más relevantes de esta definición, cabe destacar la asociación de competencia a vocablos relativos a actividad (aplicación, resolución... ) similares a la definición de la RAE y, especialmente de interés para este artículo, el carácter de integración de contenidos.

A pesar de la ingente variedad de propuestas sobre el término «competencia», al gunas características definitorias se han ido consolidado como fundamentales, destacando precisamente el carácter integrador de diferentes conocimientos para la aplicación práctica y cotidiana (Monereo y Pozo, 2007; Tiana, 2011). Además, la competencia debe contrastarse de manera aplicada en diversos contextos vitales, un «saber hacer» que recuerdael conocimiento procedimental LO GSE (Coll, Pozo, Sarabia y Valls, 1992).

Menos sencillo resulta el análisis del concepto transversalidad, puesto que no es un elemento curricular y no se describe de manera tan explícita. Junto a la transversalidad aparecen otros constructos como integración de los conocimientos, transferencia, transdisciplinariedad, interdisciplinariedad y, en los últimos documentos publicados, la globalidad de los contenidos (Lavega, Sáenz de 0 cáriz, Lasierray Salas, 2013; De la Hernán, 2015). La paradoja es que la transversalidad es anterior a la competencia; pueden encontrarse fuentes primigenias en la filosofía social de Guattari (Cole y Bradley, 2018) y en publicaciones anteriores a la irrupción competencial (Yus, 1997). La transversalidad, dando sentido a su significación, se ha trabajado desde diversos ámbitos de conocimientos, desde las matemáticas (Díaz y Poblete, 2014) hasta la educación física (Martínez, 2008; Calahorro y Carpio, 2011). La aproximación cuantitativa demuestra que la transversalidad era inexistente en la LO GSE (1990), apareció muy tímidamente en la LOE (2006), y despuntó en la LO M CE (2013) donde aparece referenciada en 21 ocasiones, desde el mismo Preámbulo del RD 1105/ 2014: «El aprendizaje basado en competencias se caracteriza por su transversalidad, su dinamismo y su 
carácter integral».

La definición original de competencia destacaba la integración de los contenidos para la mejor resolución de problemas prácticos, mostrando su carácter consubstancial con la transversalidad. La transversalidad entendida como metodología de aprendizaje competencial no aparecía tácitamente en la LOE, pero su significa ción se resolvía con la integración de conocimientos:

La inclusión de las competencias básicas en el currículo tiene varias finalidades. En primer lugar, integrar los diferentes aprendizajes, tanto los formales, incorporados a las diferentes áreas o materias, como los informales y no formales. En segundo lugar, permitir a todos los estudiantes integrar sus aprendizajes, ponerlos en relación con distintos tipos de contenidos y utilizarlos de manera efectiva cuando les resulten necesarios en diferentes situaciones y contextos (RD 1631/ 2006, p.4).

El preámbulo de la LO MCE asume la necesidad de competencias transversales desde edades tempranas, destacando el pensamiento crítico, la gestión de la diversidad, la creatividad o la capacidad de comunicar. El cambio curricular sólo se favorecerá desde una visión interdisciplinar. Sin embargo, revisiones críticas sobre innovación en educación física no destacan la transversalidad de conocimientos como metodología (Pérez Pueyo, Hortigüela, 2020). Ello puede ser debido al carácter implícito de la integración de conocimientos en el concepto de competencia y en el hecho de reafirmar la propia disciplina ante una posible disolución de la misma («entender lo motriz como un feudo exclusivamente nuestro»). Como afirma Luri (2019), sólo la existencia de las diferentes disciplinas hace posible la interdisciplinariedad.

Los cambios conceptuales imbuidos en el sistema educativo son fruto del predomino de teorías psicopedagógicas que le son contemporáneas. Q ue la acción pedagógica se apoye en constructos psicológicos nos aproxima al paradigma positivista, donde la teoría anticipa la práctica: «Los profesores no podrían ni empezar a practicar si no tuviesen al gún conocimiento teórico sobre la situación dentro de la cual actúan y alguna idea sobre lo que hay que hacer» (Carr y Kemmis, 1988, p. 126). La singular relación entre ambas ciencias justifica la rama de conocimiento que reconoce la psicología como ciencia básica y la educación como tecnologíacentrada en la intervención (Roca y Solà, 2013).

El discurso pedagógico competencial se sustenta en la inteligencia emocional y en lapsicología positiva (Prieto, 2018), complementada con la omnipresente neurociencia. Sin embargo, la psicologización del sistema educativo se inició con la LO GSE, claramente sustentada en el constructivismo (Coll, 1991). De hecho, la propia justificación de la ley evidenció que el currículo se construía con diferentes fuentes de información, destacando las fuentes pedagógica y psicológica entre la fuente epistemológica y la socio-cultural.

El enfoque cualitativo del presente artículo pretende describir las propiedades relevantes del currículo competencial para la educación secundaria obligatoria y la justificación pedagógica de la transversalidad en diferentes niveles de la administración educativa (Hernández, Fernández y Baptista, 2004). El análisis inductivo del contenido de las normativas educativas insiste en la comprensión de las teorías psicopedagógicas dominantes en la construcción humana del conocimiento (McMillan y Schumacher, 2007; Bisquerra, 2009). Además se destacará la diferencia de trato entre matemáticas (materia troncal) y educación física (materia específica) en el momento de traspasar la teoría normativa a propuestas prácticas concretas. La elección de estas materias se justifica porque ambas son materias únicas dentro de su ámbito de conocimiento en la regulación catalana, lo cual favorece el contraste.

\section{Competencias transversales para los dife- rentes ámbitos de conocimiento (LOE, 2006)}

El currículo LOE fue pionero en la formulación competencial de las enseñanzas. La ley enfatizó las competencias y su relevancia para la evaluación y promoción en la ESO, basada en el logro de los objetivos y en el grado de adquisición de las competencias correspondientes (art. 28, LOE). N o se justificaron los referentes bibliográficos de dichas competencias y, ni siquiera se enumeraron. Fueel RD 1631/ 2006 (anexol, p. 18) donde sucintamente se expuso la referencia de la U nión Europea al identificar las primeras ocho competencias básicas (CCBB) del sistema educativo español: comunica ción lingüística, matemática, conocimiento einteracción con el mundo físico, tratamiento de la información y competencia digital (TIC), competencia social y ciudadana, competencia cultural y artística, aprender a aprender $y$, finalmente, autonomía e iniciativa personal.

La Recomendación del Parlamento Europeo y del Consejo sobre las Competencias Clave (2006) fue el documento inspirador. Este documento apareció unas semanas antes delapublicación del RD 1631/2006, pero la comparación de las primeras competencias curriculares españolas presenta una gran similitud con 
siete de las competencias clave recomendadas por la Unión Europea. Convenientemente actualizada a los tiempos presentes, la Teoría de Inteligencias Múltiples (Gardner, 1995, 2003) sirvió de antecedente pedagógico. El encaje no es perfecto, ya que cada sistema educa tivo hizo suyas las inteligencias múltiples según su pósito cultural específico, pero lo cierto es que éstas se pueden ver reflejadas en seis competencias básicas (Klein, 2003; Fogarty y Stoher, 2008). Difícilmente podría plantearse una inteligencia digital cuando todavía no existía la democratización de los ordenadores personales y el acceso global a internet. Por otro lado, y en relación con la Educación Física, no hubo correspondencia entre la inteligencia motriz-cinética propuesta por Gardner y la presencia de una competencia básica que la representase. Esta desaparición se intenta subsanar con la promoción de una competencia corporal en actual estudio y discusión (Pérez Pueyo, Vicente y Hortigüela, 2019).

Las primeras competencias fueron adjetivadas como básicas, ya que eran las que a un nivel básico debían alcanzar todo el alumnado al finalizar la ESO : «La incorporación de competencias básicas al currículo permite poner el acento en aquellos aprendizajes que se consideran imprescindibles, desde un planteamiento integrador y orientado a la aplicación de los saberes adquiridos. De ahí su carácter básico». (RD 1631/ 2006, p.18).

Las competencias básicas no eran patrimonio de ninguna materia concreta, sino que todas ellas debían aportar conocimiento para asegurar su logro: «Cada una de las áreas contribuye al desarrollo de diferentes competencias y, a su vez, cada una de las competencias básicas se alcanzará como consecuencia del trabajo en varias áreas o materias» (RD 1631/ 2006, p.18). Tácitamente, laanterior citaya conteníala semilla de latransversalidad que, al no ser un elemento esencial del currículo, debía interpretarse como el trabajo coral de diferentes ma terias (Yus, 2011). El reto docente de una enseñanza basada en las CCBB determinó diferentes propuestas de aplicación didáctica (Sierra, M éndez y M añana, 2012; Sarramona, 2014).

La adaptación curricular de la administración catalana mediante el Decreto 143/2007, clasificó las ocho competencias básicas en dos grupos. El primer grupo contenía las competencias adjetivadas como transversa les. Estaba formado por la rama competencial comunicativa (lingüística y artística), metodológica (TIC, matemática y aprender a aprender) y personal (autonomía e iniciativa personal). El segundo grupo estaba formado por la rama de convivir y habitar el mun- do (conocimiento del mundo físico y conocimiento social y ciudadano). Cómo aparece esta distinción es un misterio, y carece de cierta lógica, ya que el RD ministerial había especificado el carácter transversal de las ocho competencias básicas.

A pesar de ello, la adaptación curricular autonómica fue muy respetuosa con el esquema ministerial espa ñol. Las principales innovaciones curriculares aparecieron en la presentación de la materia. Fue muy relevante la aparición de unas competencias propias de la materia, como un guiño al futuro. De manera muy discreta, puesto que se resolvía en media página del currículo de educación física (EF), se escribían pinceladas sobre competencias propias de la materia tales como desarrollo personal, práctica de hábitos sal udables, comunicación y expresión o competencia social einterpersonal. Esta novedad no era idéntica en el currículo de matemáticas, donde se enfatizaba la relación de la materia con la competencia básica homónima.

De manera similar a las disposiciones ministeriales, se destacaba también la aportación de la materia a la adquisición de las competencias básicas. En educación física (EF) se escribía que la materia contribuía esencialmente al desarrollo de las competencias centradas en convivir y habitar el mundo, o sea, las clasificadas como no transversales. Complementariamente, también existían referencias a las competencias cultural y artística, comunicativa digital y aprender a aprender. En matemáticas, después de afianzar lógicamente la vinculación con la competencia homónima, se detallaban relaciones con absolutamente todas las otras CCBB. El trato diferencial entre ambas materias era evidente.

\section{La transversalidad de las conexiones con las otras materias}

El análisis de los elementos curriculares esenciales no destacaba la transversalidad en los documentos ministeriales. Sin embargo, en el currículo autonómico catalán, al finalizar el relato de los bloques de contenido de cada asignatura, y para cada curso, se presentaban «conexiones con las otras materias». Ciertamente, el mismo currículo ya anticipaba esta declaración de intenciones: "A Aunque en la ESO los contenidos se presenten organizados por materias, para el logro de las competencias básicas es conveniente establecer relaciones entre ellos siempre que sea posible» (Decreto 143/2007). No se encuentra información justificando cómo aparecieron dichas conexiones, pero los documentos de despliegue normativo hacen referencia al 
constructivismo LO GSE, que se resistía a desaparecer de la psicologización curricular.

Se destacaba que las conexiones no eran solamente entre diferentes disciplinas, como remarcaba el currículo, sino que también debían buscarse conexiones dentro de la propia disciplina, procurando mezclar los diferentes bloques de contenido que le eran propios: "Las CCBB se desarrollarán en las diferentes materias y con actividades con diferentenivel de complejidad, que comporten conexiones entre contenidos intradisciplinares (de la propia materia) e interdisciplinares (entre diversas materias)» (art. 8.4, Decreto 143/ 2007).

Los currículos prescriptivos de cada materia explicitaban algunas de dichas conexiones, pero, en ningún caso, pretendían ser definitivas. Se invitaba al docente a enriquecer la programación con cuántas lógicas conexiones con otras materias fuera posible establecer con la finalidad última de favorecer la aplicación de lo aprendido en diferentes contextos: espíritu esencial de ser competente (ver Tablas 1 y 2 ).

Las tablas 1 y 2 muestran las propuestas de conexiones con las otras materias que aparecían en el currículo de matemáticas y de EF. Es importante fijarse que las conexiones con las otras materias se establecían a nivel

\begin{tabular}{|c|c|c|}
\hline $\begin{array}{c}\text { 1r. } \\
\text { Ciclo }\end{array}$ & Matemáticas & Educación Física \\
\hline 10 ESO & $\begin{array}{l}\text { Ciencias de la naturaleza: } \\
\text { - Concentración de una disolución. } \\
\text { - El sistema Sol - Tierra - Luna: movimientos y } \\
\text { posiciones. } \\
\text { - Estudio de las sombras. } \\
\text { - M asa, volumen, densidad. } \\
\text { - Unidades e instrumentos de medida. } \\
\text { - Lectura e interpretación de mapas del tiempo } \\
\text { atmosférico. } \\
\text { Ciencias sociales: } \\
\text { - Temperaturas y precipitaciones. Lectura, interpretación } \\
\text { y construcción de climogramas. } \\
\text { - El tiempo histórico: representación gráfica de secuencias } \\
\text { temporales. } \\
\text { - Lectura de escalas gráfica y numérica } \\
\text { - Lectura, interpretación y construcción de mesas } \\
\text { estadísticas y de gráficos de líneas, de barras y de sectores. } \\
\text { M úsica: } \\
\text { - Elementos de la armonía y el ritmo. } \\
\text { Tecnología: } \\
\text { - Escalas y acotación. }\end{array}$ & $\begin{array}{l}\text { Ciencias de la natural eza: } \\
\text { Respeto por las normas de } \\
\text { conservación del medio. } \\
\text { Lengua: } \\
\text { - Interacción oral en juegosy } \\
\text { deportes. }\end{array}$ \\
\hline Eso & $\begin{array}{l}\text { Ciencias de la naturaleza: } \\
\text { - Calor y temperatura. Números positivos y negativos. } \\
\text { Cambios de unidad. } \\
\text { - Relación entre presión, temperatura y altura. } \\
\text { - Escal as (terremotos, vientos....). } \\
\text { - O ptica (ángulos / reflexión). } \\
\text { Ciencias sociales: } \\
\text { - El tiempo histórico: representación gráfica de secuencias } \\
\text { temporales. } \\
\text { - Lectura, interpretación y construcción de mesas } \\
\text { estadísticas y de gráficos de líneas, de barras, de sectores y } \\
\text { pictogramas. } \\
\text { - Pirámides de población. } \\
\text { - Fuentes estadísticas. } \\
\text { Educación física: } \\
\text { - Control de la frecuencia cardíaca y medida del grado de } \\
\text { esfuerzo. } \\
\text { Educación visual y plástica: } \\
\text { - Construcción de formas tridimensionales. } \\
\text { - Realización de apuntes y esbozos. } \\
\text { Tecnología: } \\
\text { - Análisis de hashtags alimentarios. } \\
\text { - Ley de Ohm. } \\
\text { - Tipología de envases: formas. }\end{array}$ & $\begin{array}{l}\text { Ciencias de la naturaleza: } \\
\text { Respeto y valoración del } \\
\text { medio natural. } \\
\text { Lengua: } \\
\text { - Interacción oral en juegos y } \\
\text { deportes. } \\
\text { Desinhibición en actividades } \\
\text { comunicativas. } \\
\end{array}$ \\
\hline
\end{tabular}

de contenidos y no de las competencias básicas. La diferencia de posibles conexiones planteadas para ambas materias es sustancial. M atemáticas presentaba una rica variedad de conexiones en comparación con la escasez de propuestas para EF, siendo esta materia una de las más versátiles como crisol de aprendizajes transdisciplinares. Másalláqueunamateriafueratroncal y la otra específica, pueden intuirse también falta de reconocimiento social de la EF 0 , simplemente, escaso compromiso en su redacción curricular. O tro aspecto sustancial era que las conexiones no son biunívocas; esto es, si matemáticas de 2ํEO tenía posibles conexiones con la EF del mismo curso, resulta sorprendente que la EF no tuviera, en correspondencia, posibles conexiones

\begin{tabular}{|c|c|c|}
\hline $\begin{array}{c}\mathbf{2}^{\mathbf{0}} \\
\text { Ciclo }\end{array}$ & Matemáticas & Educación Física \\
\hline $\begin{array}{c}3^{\circ} \\
\text { ESO }\end{array}$ & $\begin{array}{l}\text { Ciencias de la naturaleza: } \\
\text { - Átomo y reacciones químicas (números grandes y } \\
\text { pequeños; expresión de números en forma de } \\
\text { potencia; ecuaciones lineales por el cálculo de } \\
\text { masas en las reacciones químicas). } \\
\text { - Nutrición y cálculo de dietas (\%, cambios de } \\
\text { unidades, gráficos). } \\
\text { Ciencias sociales: } \\
\text { - Elementos básicos de economía. Identificación de } \\
\text { los componentes económicos. } \\
\text { - Tanto por ciento, tanto por mil, tanto por uno. } \\
\text { - Impuestos directos e indirectos. IVA, IRPF, IPC. } \\
\text { - Actividades económicas. } \\
\text { Educación visual y plástica } \\
\text { - Experimentación de recursos informáticos y } \\
\text { nuevas tecnologías para la investigación y creación } \\
\text { de imágenes. } \\
\text { Educación física: } \\
\text { - Control de la frecuencia cardíaca. Conocimiento } \\
\text { de la frecuencia cardíaca máxima, de reposo y } \\
\text { cálculo de la zona de actividades. } \\
\text { - Alimentación y actividad física. } \\
\text { Música: } \\
\text { - Lectura y escritura de notación musical al servicio } \\
\text { de la audición, la interpretación, la creación y la } \\
\text { comprensión. } \\
\text { Tecnología: } \\
\text { - El coste de los servicios básicos. } \\
\text { - Diseño de una vivienda. } \\
\text { - Estrategias de ahorro energético y de agua de las } \\
\text { viviendas. } \\
\text { - Proceso industrial: producción y } \\
\text { comercialización. }\end{array}$ & $\begin{array}{l}\text { Ciencias de la naturaleza. } \\
\text { Educación para la } \\
\text { ciudadanía: } \\
\text { - Conocimiento del cuerpo } \\
\text { y de hábitos saludables. } \\
\text { Lengua: } \\
\text { - Interacción oral en } \\
\text { juegos y deportes. } \\
\text { Música: } \\
\text { - Improvisaciones } \\
\text { individuales y colectivas } \\
\text { con apoyo musical. } \\
\end{array}$ \\
\hline $\begin{array}{c}4^{\mathbf{0}} \\
\text { ESO }\end{array}$ & $\begin{array}{l}\text { Ciencias de la naturaleza: } \\
\text { - Cálculos estequiométricos en química. } \\
\text { - Fuerzas y movimientos (funciones lineales, } \\
\text { cuadráticas y de proporcionalidad inversa). } \\
\text { - Los terremotos. Escalas de medida. } \\
\text { - Edad de las rocas. Métodos de datación. } \\
\text { - Leyes de la herencia (aspectos de combinatoria y } \\
\text { probabilidad; las leyes de Mendel y los primeros } \\
\text { estudios de genética). } \\
\text { Ciencias sociales: } \\
\text { - Elementos básicos de economía. Producción, } \\
\text { productividad, inflación. } \\
\text { - Estudios estadísticos relacionados con la } \\
\text { economía. } \\
\text { Educación física: } \\
\text { - Conocimiento de las normas básicas de seguridad } \\
\text { y prevención de riesgos durante la realización de } \\
\text { actividad física. } \\
\text { - Sistemas de puntuación. } \\
\text { Educación visual y plástica: } \\
\text { - Técnicas de expresión gràfico-plástica: } \\
\text { descripción objetiva de las formas. } \\
\text { - Representaciones bidimensionales de obras } \\
\text { arquitectónicas. } \\
\text { Música: } \\
\text { - Identificación y análisis auditivo de elementos en } \\
\text { obras y prácticas musicales varias. } \\
\text { Tecnología: } \\
\text { - Documentos mercantiles básicos. Cálculo del } \\
\text { precio de un producto. } \\
\text { - Resolución de problemas tecnológicos. }\end{array}$ & $\begin{array}{l}\text { Lengua: } \\
\text { - Presentación individual o } \\
\text { colectiva de exposiciones } \\
\text { orales. } \\
\text { Educación civicoética: } \\
\text { - Reflexión sobre las } \\
\text { conductas de riesgo que } \\
\text { afectan la propia salud y la } \\
\text { de los otros. }\end{array}$ \\
\hline
\end{tabular}

Figura 2. Conexiones con las otras materias en $2 \stackrel{\circ}{ }$ Ciclo: M atemáticas y EF (Fuente: Elaboración propia). 
con las matemáticas. Se puede extender este análisis a los demás cursos de ESO y, por supuesto, al resto de materias curriculares no contempladas en las anteriorestablas. Esteincipientetrabajo entre lasmaterias debía de servir de fundamento parael desarrollo competencial consecuente.

Durante el bienio 2008-10, se inició el proceso de comprensión y delimitación de nuevos conceptos peda gógicos: transversalidad, transdisciplinariedad, interdisciplinariedad, intradisciplinariedad o transferencia. El proceso de reconstrucción periódica de los nuevos términos, reconoció la integración de conocimientos como la clave del aprendizaje competencial, comprometiendo dos procesos:

1. Transdisciplinariedad: Entre diver sas materias del currículo (conexiones con las otras materias), puesto que ser competente en la vida real exige la moviliza ción de todos los conocimientos y habilidades.

El corazón como objeto material de conocimiento puede ser abordado desde diversas perspectivas científicas u objeto formal (Luri, 2020; Roca, 2013). Según las ciencias naturales, el corazón es una bomba muscular que reparte la sangre oxigenada y carbónica de un ser vivo. Tiene cavidades (aurículas y ventrículos), válvulas y se entiende como el centro del sistema cardiovascular. Pero en EF se comprueba cómo cambian sus latidos en función de la actividad física o su recuperación en reposo. Podemos entender dónde tomar el pulso (¿tabaquera anatómica?, ¿arteria carótida?, ¿en el mismo corazón?), y el significado de sus fluctuaciones. Incluso en matemáticas podemos construir tablas estadísticas y representaciones gráficas de dicha varia bilidad y estudiar tendencias de los signos vitales... Pero también en literatura estudiamos el corazón. La lírica y la poesía hablan del corazón metafórico y romántico: «Dicesquetienescorazón, y sólo / lo dices porquesientes sus latidos; / eso no es corazón... , es una máquina / queal compásque se mueve hace ruido» (Bécquer, 1871/ 1990).

Se puede considerar una posible convergencia temporal de la transdisciplinariedad, entendiéndola como la posibilidad que todas las materias que estudian el concepto «corazón», lo puedan abordar sincrónicamente (por ejemplo, durante el segundo trimestre de 40ESO). Dicha convergencia temporal exige un esfuerzo organizativo a los equipos docentes implicados, aunque si ello no fuera posible, el aprendizaje significativo actuará como enlace a través del tiempo mediante la persistencia de los conocimientos previos (Rodríguez, 2011).
2. Interdisciplinariedad: Entendida como la mezcla de los bloques de contenidos de una misma materia. La unidad didáctica no tenía por qué pertenecer a un único bloque de contenido. La interdisciplinariedad puede ser polícroma, con el único límite de la creatividad docente.

En EF se pueden trabajar los juegos tradicionales asumiendo también el control de la resistencia aeróbica. El profesor puede ajustar las explicaciones del juego 0 la inclusión de variantes de manera semejante al control del tiempo de trabajo y del tiempo de recupera ción en un trabajo interválico. Los adolescentes mejoran la capacidad aeróbica mediante el juego sin necesitar sistemas clásicos de entrenamiento (Stumpp, 2006). En matemáticas, la comprensión gráfica de la derivada de una función en un punto (pendiente de la recta tangente), permitirá el cálculo de problemas geométricos reales o solucionar necesidades cotidianas (Zambrano, Escudero y M edrano, 2019).

\section{La irrupción de las competencias específi- cas (LOM CE, 2013)}

La segunda propuesta competencial del sistema educativo español asumió completamente la Recomenda ción del Parlamento Europeo y del Consejo sobre las Competencias Clave (2006). Simplemente existía una competencia menos porque la competencia lingüística estatal reunía las competencias de comunicación en lengua materna y de comunicación en lengua extranjera que laU nión Europea diferenciaba. El currículo LO MCE propuso las siguientes siete competencias de referencia (art. 2 RD 1105/ 2014): comunicación lingüística, competencia matemática y competencias básicas en ciencia y tecnología, competencia digital, aprender a aprender, competencias sociales y cívicas, sentido de iniciativa y espíritu emprendedor y, finalmente, conciencia y expresiones culturales.

Por lo tanto, desaparecieron la competencia de conocimiento e interacción con el mundo físico, precisamente la que estaba más directamente relacionada con la EF, y la de autonomía e iniciativa personal, pero se añadió la competencia de iniciativa y espíritu emprendedor. Como se expresó anteriormente, diversos expertos han reclamado la necesidad de reconocer una octava competencia denominada competencia corporal (Pérez-Pueyo, García, Hortigüela, Aznar yVidal, 2016), orientada a la salud y a la calidad de vida que, según el Consejo General de la Educación Física y Deportiva (COLEF) refuerce el carácter práctico de esta ense- 
ñanza y la educación integral. La LO MCE, también especifica la necesidad de reforzar aquellas competencias que tradicionalmente se vinculaban a las materias instrumentales: "Se potenciará el desarrollo de las competencias comunicación lingüística, competencia matemática y competencias básicas en ciencia y tecnología» (RD 1105/2014, p. 7). Cabe destacar que las competencias pierden adjetivación: en la LOE se definieron como competencias básicas, pero la LO M CE las definió simplemente como competencias.

El RD 1105/ 2014 remarcó el trato normativo entre materias troncales y específicas. Las troncales ( $\mathrm{Ma}$ temáticas) se estructuraron en contenidos, criterios de evaluación y estándares de aprendizaje evaluables; en cambio, las específicas (Educación Física) sólo presenta ron criterios de evaluación y estándares de aprendizaje evaluables (art. 6 LOMCE). Resulta muy destacable que no existe ningún desarrollo competencial por asignaturas puesto que el referente estatal se ciñe a las siete competencias expresadas anteriormente. No se vehiculan competencias propias o intrínsecas de cada materia, que fueran precisiones disciplinares de las siete competencias genéricas.

La adaptación curricular autonómica se diseñó en base a un esquema propio y con muchas innovaciones en el desarrollo competencial. El artículo 7 del Decreto clarifica que «las competencias básicas se convierten en los objetivos de aprendizaje final de etapa» (p.5). Es una frase que conlleva una reflexión. En primer lugar, porque en la LO M CE las competencias perdían la adjetiva ción «básicas» y, en segundo lugar, porque el currículo LOMCE no presenta objetivos de materia.

El artículo 9 del Decreto clarifica el nuevo significa do de competencia básica: «Se entiende por competencias básicas del ámbito aquellas que le son propias» (p. 6). Por lo tanto, en Cataluña, el adjetivo «básicas» refiere las competencias propias de cada ámbito (también Ila madas «específicas», art. 9.5). N omenclatura similar a la utilizada por la LOE para explicar las primeras ocho competencias (básicas), pero con una significación diferente. Este hecho podría llevar a confusión a los docentes. En las materias de referencia del artículo, exclusivas en su ámbito de conocimiento, matemáticas presenta 12 competencias básicas y educación física 8. Las demás competencias básicas se reparten en ámbito lingüístico (12), ámbito científico (15), ámbito social (13), ámbito artístico (10), ámbito cultural (10), ámbito digital (11) y ámbito personal (4). El motivo de esta enumera ción no es banal. En la administración catalana, de las 8 competencias básicas del currículo del año 2007, se ha pasado a una presentación de 95 competencias básicas en el año 2015. En escasos ocho años, el currículo requiere a los al umnos 87 competencias más al finalizar la etapa.

El currículo LOMCE no presenta objetivos de ma teria para secundaria obligatoria. Ningún currículo anterior había descartado los objetivos como referentes para las materias. Ello podría interpretarse como una innovación metodológica que apartase la denostada pedagogía por objetivos (Gimeno, 1986), por planteamientos didácticos más progresistas. Sin embargo, esta idea queda en entredicho cuando el propio decreto informa que las competencias básicas se convierten en los objetivos finales de etapa (art. 7.1 Decreto 187/ 2015). Se vinculan las competencias a objetivos complejos sujetos a la aplicación de objetivos parciales interrelacionados cuyo logro deben evaluarse al finalizar la etapa.

\section{La transversalidad del tratamiento globalizado de los contenidos}

En la LOMCE los conceptos de competencia y transversalidad se acercan. La adquisición de competencias sólo tiene sentido si se diseñan ${ }_{\text {... actividades }}$ de aprendizaje integradas que permitan al alumnado avanzar hacia los resultados de aprendizaje de más de una competencia al mismo tiempo» (RD 1105/2014, art.2, p.7). Además, el nuevo marco competencial español focaliza de manera explícita los siguientes elementos transversales (art. 6 RD 1105/ 2014):

a) La comprensión lectora, la expresión oral y escrita, la comunicación audiovisual, las TIC, el emprendimiento y la educación cívica y constitucional.

b) La igualdad efectiva entre hombres y mujeres, la prevención de la violencia de género o contra personas con discapacidad y los valores inherentes al principio de igualdad de trato y no discriminación.

c) El espíritu emprendedor, la adquisición de competencias para la creación y desarrollo de los diversos modelos de empresas y ética empresarial.

d) Laactividad física y la dieta equilibrada en el comportamiento juvenil, siguiendo las recomendaciones de los organismos competentes para favorecer una vida activa, saludable y autónoma.

e) Educación y seguridad vial, promoviendo la mejora de la convivencia y la prevención de los accidentes de tráfico, en calidad de peatón, viajero y conductor de bicicletas o vehículos.

Sin duda, elementos transversales que enriquecen la formación de los adolescentes en una etapa clave, 
aludiendo a la responsabilidad comunitaria de su enseñanza entre los diversos ámbitos del conocimiento. Desde el punto de vista de la Educación Física, es especialmente relevante la transversalidad de la actividad física, hecho que se ha puesto de manifiesto durante las semanas de confinamiento sanitario para combatir socialmente al virus Covid-19, aunque la Ley no determina con claridad la figura del profesor de Educación Física como máximo responsable y valedor de su cumplimiento.

La transversalidad curricular autonómica recuerda que las competencias clave europeas «... deben permitir el desarrollo de diferentes conocimientos de manera interactiva y transversal... Conseguirlas, permite su transferencia a otras situaciones» (Decreto 187/ 2015, art. 8.2, p.5). Se realzan dos ámbitos de conocimientos que explícitamente son denominados como transversa les: «El logro de los elementos transversales del ámbito personal y social, y del ámbito digital debe desarrollarse en el conjunto de materias... » (Decreto 187/ 2015, art. 8.5, p.5). Por lo tanto, la propuesta curricular autonómica constará de competencias (básicas) de los diferentes ámbitos de conocimientos, complementados con competencias transversales de los ámbitos digital y personal (art. 9.2).

Existen notables diferencias entre ambos ámbitos transversales. El ámbito digital está integrado en cada ámbito curricular. Esto significa que cualquier ámbito curricular no transversal ya tiene especificados los contenidos digitales correspondientes. Por ejemplo, en el currículo de EF se han incluido tres contenidos clave digitales (CCD): ergonomía y salud física (CCD 25), fuentes de información digital (CCD 7) y leguaje audiovisual (CCD 10). La responsabilidad curricular del ámbito digital debe compartirse con todo el claustro: once competencias y 28 contenidos de los cuales sólo tres aparecen en el currículo de EF.

El currículo del ámbito personal y social se publicó en julio de 2018, con lo cual su aplicación ha sido muy prudente hasta ahora. Además, este ámbito no está integrado en los currículos. Sus cuatro competencias también requieren un estudio coral por parte del claustro para garantizar su consecución al final de la etapa. De esta manera, cada profesor especialista debe responsabilizarse de las competencias básicas de su propio ámbito de conocimientos, y también de las competencias de los ámbitos transversales.

Si la transversalidad LOE era el fundamento metodológico del aprendizaje por competencias, podría mos preguntarnos por qué se diluyeron las conexiones con las otras materias. Porque a pesar del cambio normativo, el reciente documento Programar por competencias en educación secundaria obligatoria (febrero 2020), mantiene que: «Cada materia contribuye al desarrollo de diferentes competencias y, a la vez, cada competencia se adquiere como consecuencia del trabajo en diferentes disciplinas y contextos escolares de aprendizaje» (2020, p. 10).

Se indica que los aprendizajes son competenciales si son transferibles, perdurables, productivos y funciona les. Interesa especialmente la condición de transferibilidad ya que incluye el obsoleto concepto de transver salidad. Asegurar que losaprendizajes sean transferibles y útiles en contextos diferentes, exige un trata miento globalizado de los contenidos. Se sustituye la transversalidad por la globalidad, que no es un concepto innovador en educación (Torres, 2006) y que se ha utilizado ampliamente en las etapas de infantil (Molina y López, 2017) y primaria (Alsina, 2012). La transferencia de los conocimientos de la educación formal a las exigencias cotidianas de la vida real se convierte en el eje del desarrollo competencial. En psicopedagogía, el factor de generalización o transferencia explica el positivo traspaso del aprendizaje de una actividad a otra actividad semejante (Roca, 2006).

Seenfatizaque losaprendizajes son perdurablescuando no son víctimas del olvido inminente ya que el al umno se ha implicado en su adquisición. Para que esto se cumpla, son necesarias las conexiones entre los contenidos. Si la palabra «conexiones» evoca al aprendizaje significativo como condición de perdurabilidad, significa ría que el nuevo contenido se relaciona (se conecta) de manera no arbitraria con los conocimientos previos, permitiendo una integración duraderay aplicable (o sea, transferible). Si las conexiones significan relaciones entre diversas materias (globalidad), el procedimiento sería sinónimo de transdisciplinariedad; si dichas conexiones se realizan entre los bloques de contenido de la materia, el procedimiento sería sinónimo de interdisciplinariedad. La lectura de Zabala (1999) aporta lucidez al relato ya que, para el autor, la globalidad es una manera de acercarse a la realidad, mientras que la disciplina y sus derivadas (transdisciplinar, interdisciplinar... ) son los medios para conseguir su conocimiento. La per spectiva globalizadora de la enseñanza debe permitir el análisis y la comprensión de los problemas en los contextos vivenciales.

Al no redactarse explícitamente en el currículo, las posibles conexiones deben buscarse diseminadas en las normativas de apoyo didáctico. Especialmente útil es el 
documento para la Identificación y despliegue de las compe tencias básicas (diciembre 2015). El exhaustivo análisis del texto, permite extraer indicios de transversalidad de cada ámbito (ver Tabla 3). Cabe destacar que la transversalidad se establece a nivel de competencias básicas, contrariamente a las conexiones LOE vincula das a los contenidos. Indudablemente, surgen dudas sobre la sistematización coherente de las relaciones transversales extraídas. Se echan en falta vínculos de la EF con el ámbito lingüístico, especialmente cuando en las desaparecidas conexiones, aparecía como recomenda ción en todos los cursos de la ESO. Asimismo, sorprende no encontrar ninguna referencia que enlace la EF con el ámbito matemático, claramente destacada en la anterior propuestacompetencial e, indudablemente, que no se considere siquiera con el ámbito personal y social. Y dichas correspondencias deberían multiplicarse al ana lizar en profundidad todos los ámbitos curriculares.

Atreverse a plantear una didáctica más radical de la gl obalidad de contenidos conllevaría la disolución de las materias concebidas clásicamente. De esta manera, surgen propuestas de transversalidad e integración de conocimientos que aspiran a ser un reflejo real de la vida cotidiana. Estas propuestas se basan en el trabajo por proyectos, con mucha aceptación en las etapas de primaria y primeros cursos de la ESO (De Miguel, 2006). De hecho, trabajo por proyectos interdisciplinares ya se han venido haciendo desde las primeras propuestas competenciales (créditos de síntesis, trabajos de investigación o servicio comunitario basado en el aprendizaje servicio), pero ahora se trataría de extender la metodología al resto de materias. Una publicación muy reciente, Trabajo por proyectos: un aprendizaje auténtico (2019), lo caracteriza sobre la base de un gran tema transversal que permite a los alumnos resolver situaciones competenciales, puesto que en los contextos vitales se exige la participación global del conocimiento. Los centros docentes deberían alejarse de una planificación compartimentada del conocimiento porque «Todo lo que pasa en la vida real, todo lo que es auténtico, no está fragmentado, sino que es único y global» (p.2).

\section{Conclusiones}

El primer currículo competencial LOE (2006), era muy similar en la propuesta ministerial y en la adapta-

\begin{tabular}{|c|c|c|}
\hline $\begin{array}{l}\text { Competencias (básicas) } \\
\text { de la educación física }\end{array}$ & Transdisciplinariedad & Interdisciplinariedad (Intra) \\
\hline $\begin{array}{c}\text { C1 } \\
\begin{array}{c}\text { Aplicar un plan de trabajo de mejora o } \\
\text { mantenimiento de la condición física } \\
\text { individual con relación a la salud }\end{array}\end{array}$ & $\begin{array}{l}\text { Ámbito cientificotecnológico (conocimiento del cuerpo humano y del concepto de } \\
\text { salud) y el digital (ergonomía) }\end{array}$ & \\
\hline $\begin{array}{c}\text { C2 } \\
\text { Valorar los efectos de un estilo de vida } \\
\text { activo a partir de la integración de } \\
\text { hábitos saludables en la práctica de } \\
\text { actividad física }\end{array}$ & $\begin{array}{l}\text { Ámbito cientificotecnológico: } \\
\text { C12. Adoptar medidas de prevención y hábitos saludables en el ámbito individual y social, } \\
\text { fundamentadas en el conocimiento de las estrategias de detección y respuesta del cuerpo } \\
\text { humano. } \\
\text { C13. A plicar las medidas preventivas adecuadas, utilizando el conocimiento científico en } \\
\text { relación con las conductas de riesgo y dolencias asociadas al consumo de sustancias adictivas. } \\
\text { C14. Adoptar hábitos de alimentación variada y equilibrada que promuevan la salud y eviten } \\
\text { conductas de riesgo, trastornos al imentarios y dolencias asociadas ). } \\
\text { Ámbito digital: } \\
\text { C10. Fomentar hábitos de uso saludable de lasTIC vinculados a la ergonomía para la } \\
\text { prevención de riesgos (psíquicos y físicos). }\end{array}$ & $\begin{array}{l}\text { Trabajarla en todas las otras dimensiones del ámbito de la educación } \\
\text { física. } \\
\text { Competencia transversal a todos los contenidos de la materia. }\end{array}$ \\
\hline \multicolumn{3}{|c|}{$\begin{array}{l}\text { C3 } \\
\begin{array}{c}\text { Aplicar de manera eficaz las técnicas y } \\
\text { tácticas propias de los diferentes } \\
\text { deportes }\end{array}\end{array}$} \\
\hline $\begin{array}{l}\text { C4 } \\
\text { Posar en práctica los valores propios } \\
\text { del deporte en situación de } \\
\text { competición }\end{array}$ & $\begin{array}{l}\text { Á mbito de la cultura y valores: } \\
\text { C1. Actuar con autonomía en la toma de decisiones y ser responsable de los propios actos. } \\
\text { C5. M ostrar actitudes de respeto activo hacia las otras personas, culturas, opciones y } \\
\text { creencias. }\end{array}$ & $\begin{array}{l}\text { C1. A plicar un plan de trabajo de mejora o mantenimiento de la } \\
\text { condición física individual con rel ación a la salud } \\
\text { C2. Valorar los efectos de un estilo de vida activo a partir de la } \\
\text { integración de hábitos saludables en la práctica de actividad física. } \\
\text { C5. Disfrutar con la práctica de actividades físicas recreativas, con una } \\
\text { atención especial a las del medio natural. }\end{array}$ \\
\hline $\begin{array}{c}\text { C5 } \\
\text { Disfrutar con la práctica de actividades } \\
\text { físicas recreativas, con una atención } \\
\text { especial a las que se realizan en el } \\
\text { medio natural }\end{array}$ & & $\begin{array}{c}\text { C1. Aplicar un plan de trabajo de mejora o mantenimiento de la } \\
\text { condición física individual con relación a la salud. } \\
\text { C2. Valorar los efectos de un estilo de vida activo a partir de la } \\
\text { integración de hábitos saludables en la práctica de actividad física. } \\
\text { C4. Poner en práctica los valores propios del deporte en situación de } \\
\text { competición }\end{array}$ \\
\hline $\begin{array}{c}\text { C6 } \\
\begin{array}{c}\text { Planificar y organizar actividades en } \\
\text { grupo con finalidad de ocio }\end{array}\end{array}$ & Tecnol ogías digital es. & $\begin{array}{l}\text { C5. Disfrutar con la práctica de actividades físicas recreativas, con una } \\
\text { atención especial a las del medio natural. }\end{array}$ \\
\hline $\begin{array}{c}\text { C7 } \\
\text { Utilizar los recursos expresivos del } \\
\text { propio cuerpo para el } \\
\text { autoconocimiento y para comunicarse } \\
\text { con los otros }\end{array}$ & $\begin{array}{l}\text { Ámbito artístico. } \\
\begin{array}{l}\text { C7. Desar rollar proyectos artísticos disciplinarios o transdisciplinares tanto per sonales como } \\
\text { col. lectivos. }\end{array}\end{array}$ & \\
\hline $\begin{array}{c}\text { C8 } \\
\begin{array}{c}\text { Utilizar actividades con apoyo musical, } \\
\text { como medio de relación social e } \\
\text { integración comunitaria. }\end{array}\end{array}$ & $\begin{array}{c}\text { Ámbito artístico } \\
\begin{array}{c}\text { C1. U tilizar estratégicamente los elementos de los lenguajes visual, musical y cor poral para } \\
\text { anal izar las producciones artísticas. }\end{array} \\
\begin{array}{c}\text { C3. Inter pretar música de forma individual y colectiva utilizando la voz, los instrumentos, el } \\
\text { cuerpo y las herramientas tecnológicas. } \\
\text { C7. Desar rollar proyectos artísticos disciplinarios o transdisciplinares tanto per sonales como } \\
\text { colectivos. }\end{array}\end{array}$ & \\
\hline
\end{tabular}

Figura 3. Relaciones transdisciplinares e interdisciplinares en las competencias de EF (Fuente: Elaboración propia) 
ción autonómica catalana. Las primeras competencias del estado español, referente pedagógico de la educa ción básica, se mantuvieron idénticas en ambas norma tivas para los diez años del recorrido de primaria a secundaria. La transversalidad apareció al especificar que todas las materias eran responsables del logro de dichas competencias. De hecho, el concepto no estaba escrito como tal, sino como integración de conocimientos.

La adaptación autonómica de la LOE dividió las primeras ocho competencias básicas en seis transversales y dos de convivir y habitar el mundo. Dicha división no era nítida didácticamente, ya que todas las competencias eran por natural eza transversales: todas se debían lograr a través del trabajo cooperativo de varias materias. De mucha relevancia fue la aparición de las «conexiones con las otras materias» que, a pesar de al gunas debilidades definitorias, enfatizaban desde los contenidos la necesidad de pensar el currículo de manera transversal. Este aspecto tenía toda su justificación en que precisamente era la transversalidad disciplinar la base del aprendizaje competencial real. Los docentes debían comprender su práctica como integración de conocimientos, tanto a nivel de los propios bloques de contenido (interdisciplinariedad) como a nivel de romper las fronteras clásicas de la propia materia (transdisciplinariedad). Las conexiones con las otras materias apuntadas desde el currículo constituían un mural de posibles integraciones de conocimientos dónde la limitación estaba tan sólo en la creatividad docente.

El currículo competencial LOMCE (2013), asumía con más claridad la necesaria adquisición temprana de competencias transversales como el pensamiento crítico, el respeto por la diversidad o la capacidad de comunicar.También enfatizó un enfoquetransver sal de lacomprensión lectora, la expresión oral y escrita, nuevas tecnologías o educación cívica, contenidos de loscualesninguna materia queda exenta de responsabilidad. Además, se afianza la transversalidad con la redacción de elementos ineludibles en la educación de los adolescentes.

La adaptación curricular autonómica reforzó la transversalidad marcada en la ley. A parecieron ámbitos de conocimientos específicamente designados como transversales: el ámbito digital, en parte ya incluido en las propuestas curriculares, y el ámbito personal y social, de reciente publicación. Por lo tanto, la normativa convierte a los profesores en responsables de tres ámbitos disciplinares: la materia específica en relación a su formación más los dos ámbitos añadidos transversales. Ambos ámbitos transversales se evalúan al finalizar cada curso de ESO mediante la aportación de todas las ma terias. La propuesta curricular enfatiza las competencias básicas (propias) de cada materia, multiplicando las exigencias competenciales de los alumnos durante la etapa.

La programación sigue insistiendo en hacer constar posibles conexiones con las otras materias, a pesar de haber caído de los currículos. Se pueden constatar rela ciones transdisciplinares e interdisciplinares disemina das desordenadamente en la relación de competencias básicas de cada ámbito, localizadas en las orientaciones metodológicasy evaluativas. Las posiblesconexionescon las otras materias no se hallan en relación a los contenidos, sino directamente en las competencias, lo cual pa rece lógico en un currículo que las destaca sobremanera.

Los conceptos de transdisciplinariedad e interdisciplinariedad no se encuentran en ningún documento normativo actual. Contemporáneamente se ha sustituido la transversalidad por la globalidad de contenidos. U na globalidad que favorece su transferencia a situaciones reales delavida, plenamente contextualizadas con la exigencia de la cotidianeidad (Zabala, 1999). Forzando este paso y rompiendo las fronteras de los ámbitos y disciplinas, se justificaría un planteamiento peda gógico basado en proyectos educativos.

\section{Referencias}

Alsina, A. (2012). Hacia un enfoqueglobalizado dela educación matemática en las primeras edades. Revista de Didáctica de las M atemáticas, 80, 7-24.

Bécquer, G.A. (1871/ 1990). Rimas y leyendas Barcelona: Planeta S.A.

Bisquerra, R, (Coord.). (2009). Metodología de la investigación educativa (2 $2^{-}$ ed). Madrid: La Muralla S.A.

Bunes, M., Calzón, J., Elexpuru, I., Fañanas, L.T., Muñoz-Repiso, M. y Valle, J.M. (1993). Los valores en la L.O.G.S.E. Billbao: ICE-Universidad de Deusto.

Calahorro, F. y Carpio, E. (2011). Contenidos transversales e interdisciplinariedad. Una aproximación desde la educación física. Arte Y Movimiento, (4).

Carr,W. y Kemis, S. (1988). Teoría Crítica dela enseñanza. Barcelona, Martínez-Roca.

Cole, D.R. y Bradley, J.P.N (Eds.) (2018). Principles of transversality in globalization and education. Singapore: Spinger Nature.

Coll, C. (1991). Psicología y Currículum. Una aproximación psicopedagógica a la elaboración del currículum escolar. Barcelona, Paidós.

Coll, C., Pozo, J.I., Sarabia, B. yValls, E. (1992). Los contenidos de la reforma: enseñanza y aprendizaje. Barcelona: Santillana.

De la Herrán, A. (2015). University training and transversality. Tendencias pedagógicas, 10, 223-256.

De Miguel, M. (2006). M odalidades de enseñanza centradas en el desarrollo de competencias. O viedo: Ediciones de la U niversidad de 0 viedo.

Decreto 143/ 2007, de 26 de junio, por el cual se establece el ordena miento de las enseñanzas de la educación secundaria obligatoria.

Decreto 187/ 2015, de 25 de agosto, por el cual se establece el ordenamiento de las enseñanzas de educación secundaria obligato- 
ria.

Díaz, V. y Poblete, A. (2014). Resolución de problemas en matemáticas desde la transversalidad: educar en valores éticos. Revista Paradigma, 35 (2), 155-182.

Espacio Europeo de Educación Superior (2015). Proceso de Bolonia. Recuperado de http:/ / www.eees.es/ es/ eees-estructuradel-eees (Consultado el 23-07-2019).

Gardner, H. (1995). Inteligencias múltiples: la teoría en la práctica. Barcelona: Paidós.

Gardner, H. (2003). La inteligencia reformulada: las inteligencias múltiples en el siglo XXI. Barcelona: Paidós.

Generalitat de Catalunya: Departament d'Ensenyament (2009). Del currículum a las programaciones. Una oportunidad para la reflexión pedagógica en la educación básica. Barcelona: Dirección General de la Educación Básica y el Bachillerato.

Generalitat de Catalunya: Departament d'Ensenyament (2017). Competencias básicas del ámbito Educación Física. Identificación y despliegue en la ESO. Barcelona: Dirección General de Educación Secundaria O bligatoria y Bachillerato.

General itat de Catalunya: Departament d'Ensenyament (2019). Trabajo por proyectos: un aprendizaje auténtico. Barcelona: Red competencias básicas.

Generalitat de Catalunya: Departament d'Ensenyament (2020). Programar por competencias en la educación secundaria obligatoria. Barcelona: Dirección General de Currículum y Personalización.

Gimeno, J. (1986). La pedagogía por objetivos: obsesión por la eficacia (12a ed.). Madrid: Morata

Fogarty, R.J. y Stoehr, J. (2008). Integrating curricula with multiple intelligences teams, them sans threads ( 2 a ed). Thousand 0 aks: Corwin Press.

Hernández, R., Fernández, C. y Baptista, P. (2004). M etodología de la Investigación. ( 3 a ed.). M éxico, McGraw-Hill Interamericana.

Lavega Burgués, P., Sáez de 0 cáriz, U., Lasierra, G. y Salas, C. (2013). Intradisciplinariedad e Interdisciplinariedad en la adquisición de competencias: estudio de una experiencia de aprendizaje cooperativo. Revista Electrónica Interuniversitaria De Formación Del Profesorado, 16 (1), 133-145.

Le Boterf, G. (2001). Ingeniería de las competencias Barcelona: Gestión 2000.

Lévy-Leboyer, C. (2003). Gestión de las competencias, analizarlas, evaluarlas desarrollarlas. Barcelona: Gestión 2000.

Ley O rgánica 2/ 2006, de 3 de mayo, de educación (LOE, BOE núm. 106, de 4 de mayo de 2006).

Ley O rgánica 1/ 190, de 3 de octubre, de ordenación general del sistema educativo (LOGSE, BOE núm. 238, de 4 de octubre de 1990).

Ley O rgánica 8/ 2013, de 9 de diciembre, para la mejora de la calidad educativa (LOMCE, BOE núm. 295, de 10 de diciembre de 2013).

Luri, G. (2020). La escuela no es un parque de atracciones U na defensa del conocimiento poderoso. Barcelona: Ariel.

Klein, P. D. (2003). Rethinking the multiplicity of cognitive resources and curricular representations: Alternativesto'learningstyles' and 'multiple intelligences'. Journal of Curriculum Studies, 35, 45-81

Martínez, L. (2008). Educación física, transversalidady valores. Barcelona:Wolters Kluwer

M cM illan, J.H. y Schumacher, S. (2007). Investigación educativa: una introducción conceptual ( $\left.5^{a} \mathrm{ed}\right)$. Madrid: Pearson.

Molina, M. y López-Pastor, V. (2017). Educación física y aprendizaje globalizado en Educación Infantil: evaluación de una experiencia. Didacticae, 2, 89-104.

Monereo, C. y Pozo, J.I, (Coord. ). (2007). Competencias básicas. Cuadernos de Pedagogía 370, M onográfico.

Real Decreto 1631/ 2006, de 29 de diciembre, por el que se establecen las enseñanzas mínimas correspondientes a la Educación Secundaria 0 bligatoria (BOE núm. 5 , de 5 de enero de 2007).
Real Decreto 1393/2007, de 29 de octubre, por el que se establece la ordenación de las enseñanzas universitarias oficiales (BOE núm. 260, de 30 de octubre de 2007).

Real Decreto 1105/ 2014, de 26 de diciembre, por el que se establece el currículo básico de la Educación Secundaria O bligatoria y del Bachillerato (BOE núm. 3, de 3 de enero de 2015).

Recomendación del Parlamento Europeo del Consejo 2006/ 962/ CE, de 18 de diciembre sobre las competencias clave para el aprendizaje permanente (Diario O ficial de laU nión Europea L 394/ 10, de 30 de diciembre de 2006).

Pérez-Pueyo, A., García Busto, 0., Hortigüela Alcalá, D., Aznar Cebamanos, M. yVidal Valero, S. (2016). ¿Es posible una (verdadera) competencia clave relacionada con lo motriz? La competencia corporal. Revista Española de Educación Física y D eportes, 415, 51-71

Pérez-Pueyo, A., Vicente, M. y Hortigüela, D. (2019). ¿Por qué y para qué de las competencias clave en educación física?Anáisis de dos posturas contrapuestas. Retos: N uevas tendencias en Educación Física, Deportes y Re creación, 35, 7-12.

Pérez-Pueyo, A. y HortigüelaAlcalá, D. (2020). ¿Y si toda la innovación no es posible en Educación Física? Reflexiones y consideraciones prácticas. Retos. Nuevastendencias en Educación Física, Deportes y Recreación, 37, 579-587.

Perrenaud, P. (2007). Diez nuevas competencias para enseñar (5aed). Barcelona: Graó.

Prieto, M. (2018). Lapsicologización de la educación: Implicaciones peda gógicas de la inteligencia emocional y la psicología positiva. Educación XX1, 21(1), 303-320.

Resolución EDU/ 17/ 2020, de 13 de enero, de convocatoria de concurso oposición para el ingreso y acceso a la función pública docente y para la adquisición de nuevas especialidades.

Riera, J. (2005). Habilidades en el deporte. Barcelona: INDE Publicaciones

Roca, J. (2006). Psicología. Una introducción teórica. Girona: Documenta Universitaria.

Roca, J. (2013). Ciencias de la conducta: objeto material y objeto formal. Conductual, 1 (1), 4-15.

Roca, J. y Solá, J (2013). El Área de Conocimiento de CienciasPsicológicas y Educativas. En Estudios sobre Comportamiento y AplicacionesVolumen III, 217-232. Hermosillo, México: Universidad de Sonora.

Rodríguez, M. (2011). Lateoría del aprendizaje significativo: una revisión aplicable a laescuelaactual. Revista El ectrónica deInvestigación eInnovación Educativa Socioeducativa, 3 (1) 29-50.

Sarramona, J. (2014). Competencias básicas y currículum. Teoría de la Educación, 26 (2), 205-228.

Sierra, B., Méndez, A., Mañana, J. (2012) Necesidad y propuesta de un procedimiento para programar por Competencias. Aula Abierta, 40 (3), 33-46.

Stumpp, U. (2006). Adquirir una buena condición física jugando (3a ed). Barce lona: Paidotribo.

Tiana, A. (2011). Análisis de las competencias como núcleo curricular en la educación obligatoria española. Bordón. Revista de Pedagogía, 63 (1), 6375.

Torres, J. (2006). Globalización e Interdi sciplinariedad: El Currículum Integrado. Madrid: Morata.

Yus, R. (1997). La transversalidad como constructo organizativo del currículo escolar, en la antesala de la globalidad. Revista de Investigación de investigación en la escuela, 32, 43-50.

Yus, R. (2011). Competence-based education: between the rhetoric and the reality a proposal for a curricular solution. Publicaciones, 41, 141159.

Zabala, A. (1999). Enfoque globalizador y pensamiento complejo: una respuesta para la comprensión y la intervención en la realidad. Barcelona: Grá.

Zambrano, R.A., Escudero, D.I., Medrano, E.F. (2019). An introduction to the concept of derivative in high school students. Educación M atemática, 31(1), 258-280. 